\title{
$\mathrm{VII} \mathrm{CINCCI}$
}

VII Colóquio internacional sobre Comércio e Cidade

Fortaleza, 03 a 07 de Novembro de 2020

\section{O trabalho na era digital e o impacto na dinâmica urbana}

Work in the digital age and the impact on urban dynamics

El trabajo en la era digital y el impacto en la dinámica urbana.

PUGLIESE, Lívia Louzada de Toledo; Profa. Ma.; Anhanguera

livialt@gmail.com

VARGAS, Heliana Comin; Profa. Dra.; Universidade de São Paulo (USP)

hcvargas@usp.br

\section{Resumo}

O presente artigo busca discutir as transformações em curso no mundo do trabalho no século XXI e suas implicações na dinâmica urbana. Dentre os principais pontos destacados sobre as atividades laborativas estão a substituição de postos de trabalho manual por máquinas e os impactos das tecnologias da informação e comunicação; flexibilização do trabalho através de terceirização, subempregos, trabalhos temporários formais e informais; a uberização do trabalho com a submissão dos trabalhadores às plataformas digitais; a terciarização, através da ampliação de trabalhadores no setor terciário e maior complexidade deste; e o trabalho à distância, ou home office. Tais características do trabalho na era digital possuem impacto direto na dinâmica urbana, com alterações dos fluxos e das localizações das atividades. Observa-se uma flexibilização das atividades que tende alterar processos de centralização e descentralização urbana e mesclar espaços de trabalho e moradia.

Palavras-chave: Trabalho. Dinâmica urbana. Sociedade dos serviços

\section{Work in the digital age and the impact on urban dynamics}

\begin{abstract}
This article seeks to discuss the changes taking place in the world of work in the 21st century and its implications for urban dynamics. Among the main points highlighted on labor activities are the replacement of manual jobs by machines and the impacts of information and communication technologies; flexible work through outsourcing, underemployment, formal and informal temporary jobs; uberization of work by submitting workers to digital platforms; tertiarization, through the expansion of workers in the tertiary sector and its greater complexity; and distance work, or home office. Such characteristics of work in the digital age have a direct impact on urban dynamics, with changes in the flows and locations of activities. There is a
\end{abstract}




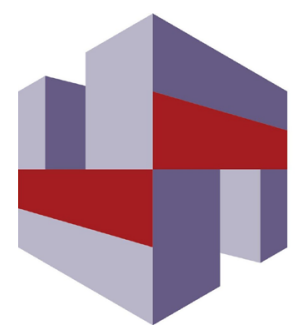

\section{CINCCI}

VII Colóquio internacional sobre Comércio e Cidade

Fortaleza, 03 a 07 de Novembro de 2020

flexibilization of activities that tends to change processes of centralization and urban decentralization and to mix work and housing spaces.

Keywords: Work. Urban dynamic. Service society

\section{El trabajo en la era digital y el impacto en la dinámica urbana}

\section{Resumen}

Este artículo busca discutir los cambios que tienen lugar en el mundo del trabajo en el siglo XXI y sus implicaciones para la dinámica urbana. Entre los principales puntos destacados en las actividades laborales están la sustitución de trabajos manuales por máquinas y los impactos de las tecnologías de la información y la comunicación; trabajo flexible mediante subcontratación, subempleo, trabajos temporales formales e informales; uberización del trabajo enviando trabajadores a plataformas digitales; terciarización, a través de la expansión de los trabajadores en el sector terciario y su mayor complejidad; y trabajo a distancia, u oficina en casa. Tales características del trabajo en la era digital tienen un impacto directo en la dinámica urbana, con cambios en los flujos y ubicaciones de las actividades. Existe una flexibilización de actividades que tiende a cambiar los procesos de centralización y descentralización urbana y a mezclar espacios de trabajo y vivienda.

Palabras clave: Trabajo. Dinámica urbana. Sociedad de servicio 


\section{Introdução}

O trabalho sempre foi uma atividade fundamental para a preservação da vida, mesmo que fosse exercido por um terceiro. Desta forma, ele participa ativamente da história da humanidade, assumindo diversos formatos que percorrem os caminhos que vão da escravidão ao emprego remunerado ou à completa autonomia.

Pochmann (2020) aponta que o trabalho, sob a perspectiva do envolvimento distinto dos seres humanos com o conteúdo de suas atividades e as relações de trabalho, sofre modificações ao longo do tempo. Ele é influenciado direta e indiretamente pelos caminhos dos sistemas produtivos e também pelas características da regulação que incide sobre o funcionamento do mercado de trabalho.

Quando a discussão sobre as relações de trabalho passa a ser territorializada, no âmbito dos estudos urbanos, seu entendimento remete à necessidade de compreensão da intensidade dos fluxos gerados nas cidades, que se constituem, até o presente momento, nos mais significativos movimentos pendulares cotidianos e, também pela identificação da origem e destino desses fluxos, com importante impacto na dinâmica da cidade.

$\mathrm{Na}$ entrada do século XXI, diante das novas tecnologias de informação e comunicação, no âmbito da revolução 4.0 , as relações de trabalho/emprego têm sido fortemente alteradas não apenas na sua quantidade e qualidade, mas também em relação às demandas locacionais. $O$ trabalho vem incorporando novas facetas, relacionadas às mudanças no sistema capitalista que conduz a formas de contratação mais flexíveis e informais, sob demanda. Com isto, o impacto destas atividades no território também tende a se alterar, tendo em vista a relação simbiótica entre elas.

Diante desse cenário o presente trabalho tem como intenção delinear, a partir das mudanças que vem sendo observadas na relação trabalho/emprego, os possíveis impactos territoriais dessas mudanças em termos da vitalidade urbana, dos índices de mobilidade, da manutenção das centralidades, das novas demandas locacionais e de novos formatos arquitetônicos. Para isto parte-se de uma revisão bibliográfica sobre as mudanças no trabalho que vem sendo observadas buscando identificar as novas demandas locacionais decorrentes dessas mudanças e os possíveis impactos na vitalidade urbana.

\section{Tendências do mundo do trabalho}

O mundo do trabalho se altera ao longo do tempo sob influência das modificações econômicas, que impactam o desenvolvimento dos sistemas produtivos, e das regulações que incidem sobre o mercado de trabalho. Sendo assim, Pochmann (2020) afirma que atualmente vivemos no Brasil uma transição para uma sociedade de serviços, que reflete um precoce processo de desindustrialização. Esta transição vem acompanhada de mudanças significativas no mercado de trabalho, que serão melhor exploradas a seguir.

Ricardo Antunes (2005) utilizou o termo "nova morfologia ou nova polissemia do trabalho" ao discutir as complexas relações que têm se criado no mundo do 
trabalho no século XXI, revelando um processo heterogêneo e complexo, ao que o autor chamou de "multifacetado, polissêmico e polimorfo". A polissemia está relacionada ao fato de o trabalho adquirir uma multiplicidade de significados, dependendo do contexto. Tradicionalmente a classe trabalhadora estava relacionada ao setor secundário e apresentava relativa uniformidade nas suas características. No entanto as formas de trabalho são cada vez mais heterogêneas nas funções desempenhadas e nas formas de contratação. Vem ocorrendo a redução dos trabalhadores no setor industrial tradicional, dando lugar a formas mais desregulamentadas e flexíveis de trabalho, com menos empregos formais.

Portanto a nova morfologia do trabalho explicada por Antunes (2005) extrapola os trabalhadores produtivos, para todo aquele que participa do processo de valorização do capital. Inclui também atualmente os trabalhadores improdutivos, cujo trabalho se dá na forma de serviço, para uso público ou do capitalista, mas não é necessariamente um elemento diretamente produtivo no processo de valorização do capital. No capitalismo contemporâneo há uma conexão profunda entre trabalho produtivo (proletariado industrial) e improdutivo (assalariados do setor de serviços), portando a soma dos dois configura a noção ampliada da classe trabalhadora contemporânea.

Esta visão inclui uma noção mais interligada entre o trabalho produtivo e improdutivo ${ }^{1}$, termos cunhados inicialmente por Smith e revisitados por Marx. Isto porque no período histórico em que conceito foi desenvolvido, as atividades ditas improdutivas (ligadas ao setor terciário) possuíam pouca relevância econômica e social (VARGAS, 1985, 2001; KON, 1992). No período atual o setor terciário ampliou sua participação com relação à quantidade de mão de obra empregada e importância do mercado econômico.

Esta amplificação da complexidade e fragmentação da classe trabalhadora tem por essência o reconhecimento de uma mudança da estrutura econômica e uma transformação nos processos de trabalho. Existem algumas características principais das transformações do mundo do trabalho no século XXI que serão sistematizadas a seguir nos seguintes tópicos: a) substituição de postos de trabalho por máquinas; b) flexibilização e desregulamentação do trabalho; c) uberização do trabalho; d) terciarização; e) trabalho à distância.

\subsection{Substituição de postos de trabalho por máquinas}

A reestruturação produtiva do capital está ligada à busca por empresas enxutas, com menores custos de produção para concorrerem no mercado global. Os processos de produção estão sendo revistos, as máquinas estão assumindo atividades manuais e a informática automatizando processos. Têm sido utilizados

\footnotetext{
${ }^{1}$ Segundo a classificação exposta por Marx (1996), as atividades eram divididas entre produtivas e improdutivas. $\mathrm{O}$ trabalho produtivo estava relacionado à produção de bens materiais, tangíveis, e que produziam mais valia. Está relacionado ao capital industrial, que poderia incluir parte do capital agrícola. O que levava à categoria de trabalho improdutivo as atividades que não criam bens materiais, o que chamamos de atividades terciárias, ou que criem bens tangíveis, mas não gerem mais valia. Marx (1996) também apresentava certa flexibilização a esta classificação, compreendendo que certas atividades de serviços eram necessárias ao processo de produção e, portanto, deveriam ser consideradas produtivas, criadoras de valor e de mais valia, como o caso dos serviços de transporte, armazenagem e distribuição de mercadorias.
} 
recursos como downsizing, produção enxuta, novos modos de gestão do trabalho e processos de terceirização (ANTUNES, 2005; POCHMANN, 2020; RIZEK, 2012).

Destaca-se especialmente o crescimento da componente intelectual do trabalho, com a implantação de sistemas de informática, das telecomunicações e dos sistemas de gerenciamento. Isto modifica as formas de trabalho tanto nas atividades industriais quanto nos setores dos serviços e comunicações, dotando ambos trabalhos de tecnologia de ponta.

A tecnologia está criando algoritmos para que as máquinas passem a aprender com os processos que vão ocorrendo, assim ela progressivamente se torna capaz de tomar decisões. Para além da indústria 4.0 se desenvolve a internet das coisas. Os objetos são conectados à rede e passam a interagir entre si e com as pessoas, alterando assim as relações de trabalho e reduzindo a necessidade de mão de obra não qualificada.

Como consequência aumenta a demanda por trabalhadores mais polivalentes e multifuncionais. Existe uma migração do perfil de trabalhadores mais especializados, que atuaram dentro da cultura fordista, para um perfil de trabalhador mais flexível, polivalente, que tende a se adaptar melhor às mudanças constantes que ocorrem no mercado de trabalho (ANTUNES, 2005; FRANCESCONI, 2017).

\subsection{Flexibilização e desregulamentação do trabalho}

O capital necessita cada vez menos de trabalho estável. As empresas mais compactas reduzem os trabalhadores estáveis em empregos formais. Dá-se lugar a formas de trabalho mais desregulamentadas e por períodos limitados (não permanentes), se tornando uma modalidade habitual da vida cotidiana contemporânea. Observa-se progressivamente a terceirização e a flexibilização do trabalho em substituição ao modelo tradicional por tempo indeterminado e carteira assinada.

Com isto aumentam os trabalhos por conta própria e o emprego assalariado informal, que perdem o acesso aos direitos sociais e trabalhistas. Este quadro leva ao crescimento do desemprego estrutural e a consequente precarização das atividades de trabalho, onde maiores parcelas da classe trabalhadora não têm acesso ao sistema público de proteção social e trabalhista. Isto inclui uma ampla gama de nomenclaturas e modalidades de trabalho emergentes, como terceirizados, economia informal, os desempregados, subcontratados, part-time, trabalhos temporários (ANTUNES, 2005; POCHMANN, 2020; RIZEK, 2012).

Se alteram as relações entre trabalho e sociedade, seja no registro do trabalho que se descola dos dispositivos do emprego para se desdobrar nas formas variadas de trabalho precário, intermitente, descontínuo, e que tornam inoperantes as diferenças entre o formal e o informal [...] tornando igualmente indiscerníveis as diferenças entre emprego e desemprego, entre trabalho e não-trabalho (TELLES, 2006, p. 174).

Essa condição tem ocorrido tanto nas atividades industriais, como no setor terciário. Um exemplo prático de como o trabalho assalariado formal tem perdido força recentemente é apresentado por Rizek (2012), a respeito da indústria de confecção de roupas e de reciclagem na Zona Leste de São Paulo. Ao invés das atividades de trabalho ocorrerem formalmente em ambientes fabris, as atividades produtivas se desenvolvem nas casas dos trabalhadores. O trabalho possui 
características associativas "onde o encolhimento do emprego assalariado teria deixado um aparente vazio, uma ausência relativa de relações de trabalho" (p.46).

Pochmann (2020) aponta que aconteceram transformações no sistema público de relações de trabalho que levaram à uma "desestruturação do funcionamento do mercado de trabalho brasileiro e a ascensão do sistema privado de relações entre o capital e o trabalho (contratualismo individual)" (p. 96). Na década de 1990 ocorreu o início da flexibilização da legislação trabalhista e social, com a abertura de novas formas de contratação do trabalho assalariado, embasando legalmente a terceirização das atividades que não eram fins das empresas. Outra ação ocorrida na década de 1990 facilitou a expansão do trabalho no regime de Pessoa Jurídica (PJ), em geral para substituir cargos de alta remuneração nas empresas.

Já nos anos 2000, políticas públicas voltadas para as micro e pequenas empresas instituíram a forma do Micro Empreendedor Individual (MEI) na perspectiva de formalização das ocupações por conta própria. Já em 2016 foram instituídas mudanças como a legislação que universalizou a terceirização dos contratos de trabalho, a reforma trabalhista, a Emenda Constitucional 9512 e as propostas de reformulação do sistema público de aposentadoria e pensão. $O$ conjunto destas medidas aprofundou as mudanças em curso e o rompimento com o padrão corporativo de organização social.

\subsection{Uberização do trabalho}

Ligada à tendência de flexibilização do trabalho existe uma especificidade que tem recebido a denominação de uberização do trabalho e que merece destaque. Esta expressão não está limitada à empresa Uber, nem se iniciou com ela, embora ela ilustre muito bem o fenômeno. Tanto esta quanto outras plataformas digitais são um resultado de um processo de transformação no mundo do trabalho, ao mesmo tempo que materializam um novo estágio desse processo, em que novas alterações da contratação do trabalho ocorrem mediante o avanço tecnológico. "O elemento central catalisado pelas plataformas são as novas formas de dispersar o trabalho sem perder o controle sobre ele" (ABILIO, 2019, p.2).

Segundo Abílio (2019) "a definição de uberização do trabalho se refere a uma nova forma de gestão, organização e controle do trabalho que se afirma como tendência global no mundo do trabalho" (p. 2). Desta forma, representa o extremo do trabalho sob demanda, ao que também se usa o termo de trabalhador just-intime e o crowdsourcing. Estes termos visam sinalizar um novo estágio que a terceirização alcançou, em que "o trabalho não é mais transferido a empresas subcontratadas, mas sim para um grande número de "usuários-trabalhadores". ( $p$. 4) Assim é um elemento central do processo de informalização do trabalho.

Desta forma o trabalhador, que não é mais contratado, mas sim se cadastra em uma plataforma, é quem assume os custos e riscos da atividade que exerce. Ele está desprovido de direitos trabalhistas, além de não ter garantias sobre sua carga horária e sua remuneração. O tempo do trabalho também muda, pois o trabalhador está todo o tempo disponível ao trabalho, mas ao iniciar a jornada de trabalho não sabe ao certo quanto de trabalho e remuneração terá até o final do dia, pois seu trabalho é sob demanda.

\subsection{Terciarização}


Com a especialização e a terceirização dos sistemas produtivos, principalmente após a segunda metade do século passado, passou-se a observar também o aumento das atividades de serviço como apoio aos sistemas produtivos. O setor terciário passou a se destacar com sua crescente participação na população economicamente ativa (PEA) e com a incorporação do progresso tecnológico.

Pochmann (2020) salienta que uma das tendências estruturais do mundo do trabalho no Brasil é a atual transição antecipada para a sociedade de serviços, cuja alteração significativa pode ser observada no próprio funcionamento do mercado de trabalho. Antunes (2005, p. 76 ) completa que "vem ocorrendo uma redução do proletariado industrial, fabril, tradicional, manual, estável e especializado, herdeiro da era da indústria verticalizada do tipo taylorista e fordista".

Os dados apresentados por Pochmann (2020) na Tabela 1 ilustram a migração de uma sociedade urbana industrial (o que se deu no Brasil entre as décadas de 1930 e 1980) para o mundo do trabalho na sociedade de serviços, o que se iniciou na década de 1980, conforme apontado por Vargas (1985) e está em processo até hoje.

Progressivamente a perda de postos de trabalho não fica restrita ao setor industrial. O próprio setor de serviços também passa por mudanças, com a introdução de tecnologias e de modos de gestão mais eficientes visando a redução de trabalhadores e o enfrentamento da concorrência com outras empresas, dentro da lógica de mercados vivida inicialmente pela indústria.

\section{Tabela 1 - Evolução da população total, ocupada e desocupada em 1980 e 2018 no Brasil}

\begin{tabular}{lrrrc}
\hline \multicolumn{1}{c}{ Itens } & $\begin{array}{c}\mathbf{1 9 8 0} \\
(\mathrm{em} \mathrm{mil})\end{array}$ & $\begin{array}{c}\mathbf{2 0 1 8} \\
(\mathrm{em} \mathrm{mil})\end{array}$ & $\begin{array}{c}\text { Variação absoluta } \\
\text { anual (em mil) }\end{array}$ & $\begin{array}{c}\text { Variação relativa } \\
\text { anual (em \%) }\end{array}$ \\
\hline População Total & 119.002 & 208.495 & 2.355 & 1,5 \\
PEA & $43.236(100 \%)$ & $105.197(100 \%)$ & 1.631 & 2,4 \\
PEA ocupada & $42.026(97,2 \%)$ & $93.002(88,4 \%)$ & 1.342 & 2,1 \\
$\quad$ Primário & $12.997(30,1 \%)$ & $8.455(8,0 \% \%)$ & -119 & $-0,8$ \\
Secundário & $12.042(27,8 \%)$ & $18.622(17,7 \%)$ & 173 & 1,1 \\
$\quad$ Terciário & $16.987(39,3 \%)$ & $65.925(62,7 \%)$ & 1.288 & 3,6 \\
PEA desocupada & $1.210(2,8 \%)$ & $12.195(11,6 \%)$ & 289 & 6,3 \\
\hline
\end{tabular}

Fonte: Elaboração de Pochmann (2020) a partir de dados do IBGE²

\subsection{Trabalho à distância}

Outra tendência apontada é a expansão do "trabalho em domicílio", ou "trabalho produtivo realizado em espaço doméstico", ou o termo mais comum: home office. Esta mudança da localização dos postos de trabalho se relaciona com a desconcentração do processo produtivo e expansão das pequenas e médias unidades produtivas. É viabilizada pela progressiva utilização da telemática ou teleinformática (combinação entre os sistemas de telecomunicação com tecnologias

\footnotetext{
2 Dados do Instituto Brasileiro de Geografia e Estatística (IBGE): Censo demográfico: 1980 e Pesquisa Nacional por Amostra de Domicílios Contínua de 2018.
} 
da informação e a microeletrônica) e pela flexibilização do trabalho (ANTUNES, 2005).

Observamos que com o avanço do trabalho imaterial, o local de trabalho vem perdendo a centralidade anterior do labor material. A flexibilidade do local e horário de trabalho tem se ampliado nos últimos anos e atingiu grandes proporções com a pandemia do novo Corona Vírus, que atingiu o mundo em 2020. Diversas empresas que já experimentavam pontualmente este sistema de trabalho à distância, tiveram que ampliar esta modalidade durante a pandemia, onde foi necessário o isolamento social. Setores de serviços que ainda não haviam experimentado tal forma de trabalho se viram obrigados a implantar de forma abrupta, experimentando seus ônus e bônus de uma forma não planejada. E o setor do comércio, que experimentava a progressiva implantação de e-commerce em alguns segmentos também teve que se adaptar à nova realidade.

\section{Relações de trabalho/emprego e a dinâmica urbana}

Assim como no mundo do trabalho, a dinâmica urbana também se modifica ao longo do tempo sob influência de diversos fatores, em especial pelas transformações das atividades econômicas no território. Estas estão relacionadas os fluxos de mercadorias e pessoas, dentre os quais estão os trabalhadores. Estes fluxos gerados possuem dinamismos diferenciados entre os três principais setores econômicos (primário, secundário e terciário).

A localização das atividades econômicas nas cidades obedece às normativas que incidem sobre o desenvolvimento urbano, como os Planos Diretores e leis de uso e ocupação do solo. Mas estes regramentos não são suficientes para determinar suas localizações nas cidades, que também são regidas pelas leis do mercado.

Vargas (2015) aponta que as atividades de comércio e serviços são atraídas pelos seus potenciais consumidores, ou seja, é o fluxo que atrai o comércio e ele se instalará onde a intensidade do fluxo for significativa. Além disto, a qualidade do fluxo (intensidade de público e renda) influencia o tipo de comércio que se instala no local.

Reforçamos assim como o trabalho se relaciona com a dinâmica urbana, com seus usos e fluxos. E após a exposição das mudanças em curso no mundo do trabalho contemporâneo no tópico acima, buscaremos discutir suas implicações no território.

Com relação à substituição de postos de trabalho manual por máquinas, esta teve seu principal impacto nos processos de produção, com redução da porcentagem da população economicamente ativa no setor secundário. Os deslocamentos pendulares para as tradicionais fábricas diminuíram. Estas transformações tendem a gerar uma descentralização das atividades e consequentemente demandas locacionais poderão ser revisadas. Algumas destas antigas plantas inclusive tiveram que se reinventar, destinando parte dos seus espaços para centros empresariais e de logística, tendo em vista que com o avanço da tecnologia e a redução de funcionários não necessitavam mais de tanto espaço.

Os avanços dos serviços digitais também trazem mudanças na localização tanto na oferta dos serviços quanto na demanda, com a mudança da localização dos consumidores dos comércios e serviços ofertados. Conforme Vargas (2020, 
p.20), "na atualidade, as estratégias dos negócios vão adquirir maior importância do que as localizações estratégicas".

A flexibilização e desregulamentação do trabalho, que se relaciona tanto com a terceirização das atividades quanto com o trabalho parcial, temporário e informal, também possui impacto na dinâmica urbana. Os fluxos de deslocamento casa-trabalho, que ocorriam em um horário pré-determinado e com uma quantidade fixa, passa a ser mais variável, ocorrendo em diferentes horários e com intensidade flutuante ao longo dos dias.

Assim como o trabalho e os trabalhadores precisam ser flexíveis, seus espaços físicos e localidades também o são. As atividades econômicas perdem progressivamente sua capacidade de estruturação e determinação sobre os territórios urbanos, devido à desorganização dos fluxos urbanos antes estabelecidos. Telles (2006) aponta que com o processo de desconexão entre trabalho e empresa, os tempos da vida e os tempos do trabalho tendem a se articular sob novas formas. Isto porque as antigas relações que antes articulavam emprego e moradia, trabalho e família, trabalho e não-trabalho passam a não estarem mais presentes.

Rizek (2012) identifica a porosidade de atividades de produção em novos territórios, com o surgimento de zonas cinzentas. O encolhimento formal do trabalho resulta em outras inserções territoriais, superando as áreas das cidades com funções claramente definidas entre o morar e o trabalhar. Em territórios periféricos moradia e trabalho se entrelaçam em fluxos de produção e de circulação de mercadorias, estabelecendo as zonas indiferenciadas.

Os processos contemporâneos discutidos acima, como a financeirização e transformação das relações de trabalho (e com o trabalho) apontam para a "dissolução dos vínculos de estruturação que desde a revolução industrial desenhavam arranjos e cadeias produtivas pela proximidade de mercados e pela polarização e concentração da força de trabalho" (RIZEK, 2012, p. 42). Os espaços vão se reformulando de uma forma discreta, sem que as modificações sejam percebidas imediatamente. Progressivamente os territórios da moradia e os do trabalho se misturam e percebem-se relações e formas de trabalho mescladas.

Um dos exemplos trazidos por Rizek (2012) é a Zona Leste da cidade de São Paulo, onde haviam se consolidado os bairros dormitórios e que passam progressivamente a ser territórios produtivos. Mas isto ocorre com uma nova morfologia, pois não se observam unidades industriais. São oficinas de costura onde os trabalhadores (majoritariamente trabalhadoras) moram e trabalham no mesmo espaço, em uma situação bastante diferente das atividades de home office comentadas acima. São aglomerados de oficinas de costura individualizadas, terceirizadas ou subcontratadas em cadeia por outras unidades maiores que subcontratam costureiras com ou sem máquinas para tarefas finais da cadeia de confecções.

A discussão sobre a uberização do trabalho, ou o trabalho sob demanda, também possui grande impacto sobre a alteração dos fluxos de trabalhadores na cidade. De Stefano (2016 apud ABILIO, 2019) estabelece duas categorias (que não são estanques) dentro do trabalho mediado por plataformas: o crowdwork se refere aos trabalhos que são realizados online, o que significa que independem da localização geográfica de trabalhadores, plataformas e clientes (a Amazon 
Mechanical Turk ${ }^{3}$, por exemplo) para ser executados; já o work on demand abarca trabalhos que são oferecidos online mas têm seu local de execução determinado (como o trabalho dos motoristas da Uber ou entregadores de comida ou lfood).

Com relação à terciarização, no contexto da ascensão na sociedade dos serviços apresentada acima, as atividades terciárias possuem grande impacto na dinâmica urbana. Observando a pesquisa de mobilidade realizada pela Confederação Nacional do Transporte e pela Associação Nacional das Empresas de Transportes Urbanos (CNT, NTU, 2017), aplicada nos municípios brasileiros com mais de 100 mil habitantes (309 municípios que são responsáveis por $56 \%$ da população brasileira, segundo dados do IBGE) (Gráfico 1), o 'trabalho' é o principal motivo de deslocamentos, correspondendo a $53,3 \%$ dos deslocamentos. Ele está relacionado a diversos setores de atividades. Os motivos 'fazer compras', 'realizar tratamento de saúde' e 'estudar' somam 32,4\% e estão relacionados ao "consumo" de atividades terciárias.

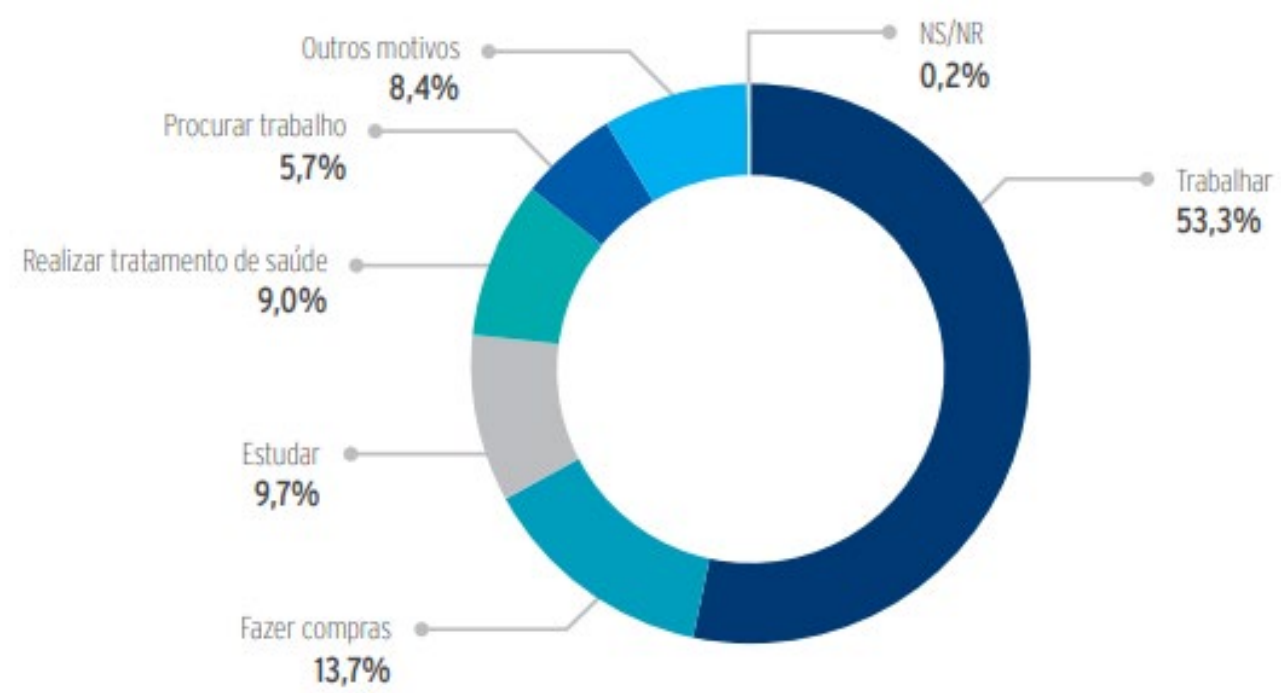

Gráfico 1 - Motivos das viagens realizadas Fonte: CNT: NTU, 2017

*Pergunta feita para os indivíduos com 15 anos ou mais que realizam deslocamentos (todos os dias, 3 a 4 dias ou 1 a 2 dias). Base de dados: 7.604 deslocamentos para os 6.571 respondentes. Esta variável aceita respostas múltiplas e os percentuais estão calculados com base no total de respostas, somando-se assim 100\%.

Conforme explicado anteriormente, os serviços são uma tendência da nova morfologia do trabalho, responsáveis por 63\% da PEA em 2018, conforme tabela 1. Mas se faz necessário estabelecer uma diferenciação entre as suas diversas categorias. Isto porque cada uma delas possui desdobramentos específicos no mundo do trabalho, especialmente com relação aos recursos humanos envolvidos, e também diferentes impactos nas territorialidades, como as quantidades e direcionamentos dos fluxos de pessoas, perfis de consumidores, proximidade entre outros empreendimentos e suas demandas locacionais.

\footnotetext{
${ }^{3}$ A Amazon Mechanical Turk (MTurk) funciona como um mercado virtual em que são publicadas diversas tarefas com um valor pré-determinado. Geralmente são trabalhos simples e repetitivos, com pequenas tarefas que computadores teriam dificuldade de fazerem sozinhos inicialmente. Classificar o conteúdo de fotos em um banco de dados, por exemplo, para treinar uma inteligência artificial para fazer isto sozinha posteriormente.
} 
Vargas (2020) afirma que o setor terciário é responsável pela vitalidade urbana. Algumas categorias dele induzem fluxos e outras se valem destes fluxos para a sua implantação. As diferentes preferências locacionais possuem relação direta com a dinâmica urbana, que inclui os usos do solo e também os fluxos de pessoas e de mercadorias. Segundo a autora, as categorias do setor terciário, que incluem comércio e serviços (públicos e privados), possuem subdivisões cada vez mais complexas e diferentes demandas por localização na cidade:

\begin{abstract}
as relações das atividades terciárias (oferta) com a demanda (empresas, governo e indivíduos) devem ser compreendidas no seu rebatimento espacial, pois tais atividades são ao mesmo tempo causa e consequência do deslocamento de pessoas, bens e serviços no território, refletindo-se enfaticamente na qualidade de vida urbana (p.3)
\end{abstract}

Alguns serviços exigem a presença do consumidor no local onde ele é ofertado, como academia, hospedagem ou educação. Já outros são realizados à distância, sem conexão com a localização, como serviços de projeto de arquitetura, ou são realizados no local especificado pelo consumidor, como os serviços manutenção e limpeza. Já no caso do comércio, a venda dos produtos é feita majoritariamente na própria loja, embora o cenário esteja se alterando com as lojas virtuais.

Outro ponto de destaque na relação entre trabalho e dinâmica urbana, são as grandes instituições, que concentram em um só local muito empregos, tanto do setor privado como do público. E além disto alguns serviços públicos também possuem a característica de atrair o público em geral que precisa acessar este serviço. Sendo assim, estes serviços são indutores de fluxo de pessoas. Isto atrai comércios e serviços que irão se valer deste fluxo de pessoas (consumidores) deste local.

Por fim, a última tendência discutida sobre as transformações do mundo do trabalho foi o trabalho à distância, resultado da flexibilização tanto das formas de trabalho quanto das suas localizações. As atividades podem passar a serem feitas remotamente, se valendo frequentemente de trabalhos em casa (home office), ou mesmo as empresas estão pulverizando suas sedes pelo espaço urbano, ou utilizando espaços de trabalhos compartilhados (coworkings). Tanto os trabalhadores formais de longo prazo e carteira assinada quanto os informais e temporários, progressivamente estão utilizando estas modalidades de trabalho à distância, seja de forma permanente ou apenas alguns dias por semana.

\title{
4 Considerações finais
}

O presente trabalho buscou discutir as relações entre a dinâmica urbana e o trabalho, dentro das suas diferentes atividades econômicas e formalizações de contratação. Para isto apresentou as transformações recentes no mundo do trabalho e o impacto dos diferentes setores econômicos na organização do território e seus fluxos.

É necessário pensar o impacto causado nas cidades pelas transformações do mundo do trabalho, sobretudo com relação ao crescimento do setor de serviços, a flexibilização das formas de contratação, com contratos informais ou formais por tempo determinado, e a precarização das formas de trabalho. A uberização do trabalho é uma exacerbação destas questões, onde o trabalhador passa a ser 
solicitado sob demanda diretamente pelo consumidor final, intermediado pelas novas empresas de tecnologia.

Diversas empresas têm alterado a concentração de funcionários, tanto pela terceirização de suas atividades como pela adesão ao home office, de forma permanente ou algumas vezes por semana. Alguns edifícios comerciais voltados a escritórios tendem a ficar menos ocupados e precisarão rever a sua forma de ocupação para garantirem a viabilidade econômica.

No universo da arquitetura os impactos das transformações no mundo do trabalho possuem um rebatimento claro nos espaços de trabalho, que também precisam ser mais flexíveis, e no mundo do urbanismo afeta o cotidiano da vida do trabalhador, suas relações sociais, seu perfil e capacidade de compra, os locais da cidade que ele acessa, os fluxos e os horários de movimentação.

Assim, as transformações no mundo do trabalho e a crescente implementação das novas tecnologias de informação e comunicação estão levando a uma flexibilização que tende a criar novas territorialidades, alterando processos de centralização e descentralização de atividades. Se faz necessária uma mudança na forma de pensar as relações sociais, os fluxos e, consequentemente, as cidades.

\section{Referências}

ABILIO, Ludmila C. Uberização: Do empreendedorismo para o autogerenciamento subordinado. In: Psicoperspectivas. Chile, n. 18, n. 3, Nov. 2019.

ANTUNES, Ricardo L. C. O caracol e sua concha: ensaios sobre a nova morfologia do trabalho. São Paulo: Boitempo, 2005

CONFEDERAÇÃO NACIONAL DO TRANSPORTE (CNT); ASSOCIAÇÃO NACIONAL DAS EMPRESAS DE TRANSPORTES URBANOS (NTU). Pesquisa Mobilidade da População Urbana 2017. Brasília: CNT: NTU, 2017.

FRANCESCONI, Lea. Crises mundiais, mudanças nas formas do trabalho e as repercussões no trabalho docente. In: XII ENANPEGE, Porto Alegre, 12 a 15 out. 2017. Anais do XII ENANPEGE. Porto Alegre: ANPEGE, 2017.

KON, Anita. A Produção Terciária. O Caso Paulista. São Paulo: Nobel. 1992.

MARX, Karl. O capital: crítica da economia política, Livro I, Volume I. São Paulo: Ed. Nova Cultural, 1996.

POCHMANN, Marcio. Terceirização desregulada e seus efeitos no mercado de trabalho no Brasil. In: Revista do TST. V. 80, n. 3, Brasília, jul/set 2014

Tendências estruturais do mundo do trabalho no Brasil. Ciênc. saúde coletiva, Rio de Janeiro, v. 25, n. 1, p. 89-99, Jan 2020. Disponível em: $<$ http://www.scielo.br/scielo.php?script=sci_arttext\&pid=S141381232020000100089\&Ing=en\&nrm=iso>. Acesso em 11 mai. 2020.

RIZEK, Cibele Saliba. Trabalho, moradia e cidade: zonas de indiferenciação?. Rev. bras. Ci. Soc., São Paulo, v. 27, n. 78, p. 41-49, Fev. 2012. Disponível em: 
<http://www.scielo.br/scielo.php?script=sci_arttext\&pid=S0102-

$69092012000100003 \&$ Ing=en\&nrm=iso>. Acesso em 20 dez. 2019.

TELLES, Vera da Silva. Mutações do trabalho e experiência urbana. Tempo Social, v. 18, n. 1, p. 173-195, 1 jun. 2006.

VARGAS, Heliana Comin. As atividades terciárias e o desenvolvimento regional. Dissertação de Mestrado. São Paulo: FAUUSP, 1985.

Espaço terciário: o lugar, a arquitetura e a imagem do comércio. São Paulo: Senac, 2001; Barueri: Manole, 2018.

A localização comercial não se define por decreto. Ensaio, 2015. Disponível em: http://www.labcom.fau.usp.br.

. Comércio, serviços e cidade: Subsídios para gestão urbana. In: Revista

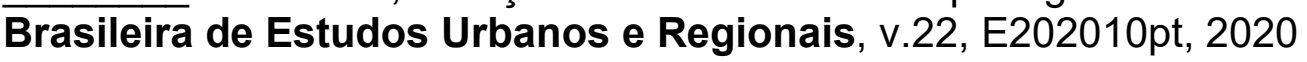

